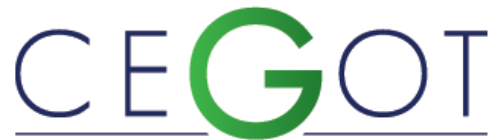

Centro de Estudos de Geografia e Ordenamento do Território
Geografia e Ordenamento do Território, Revista Eletrónica Centro de Estudos de Geografia e Ordenamento do Território http://cegot.org Carvalho, Carla

Universidade do Estado do Rio Grande do Norte, Departamento de Economia, Campus Avançado Profá. Maria Elisa De A. Maia - Pau dos Ferros. 59.990-000, Rafael Fernandes, Brasil. carvcarolc@gmail.com

\author{
ALVES, LARISSA \\ Universidade do Estado do Rio Grande do Norte, Departamento de \\ Economia, Campus Avançado Profá. Maria Elisa De A. Maia - Pau dos \\ Ferros. \\ 59.990-000, Rafael Fernandes, Brasil. \\ larissa0185@gmail.com \\ Sousa Junior, ALMIR \\ Universidade Federal Rural do Semi-Árido, Departamento de Engenharia \\ e Ciências Ambientais \\ 59.625-900, Mossoró, Brasil \\ almir.mariano@ufersa.edu.br
}

\title{
Experiências de Ordenamento Territorial Urbano na América Latina: o contexto do Brasil
}

\section{Experiences of Urban Territorial Planning in Latin America: the context of Brazil}

Referência: Carvalho, Carla; Alves, Larissa; Sousa Junior, Almir (2019). Experiências de Ordenamento Territorial Urbano na América Latina: o contexto do Brasil. Revista de Geografia e Ordenamento do Território (GOT), n.018 (Dezembro). Centro de Estudos de Geografia e Ordenamento do Território, p. 233-255, dx.doi.org/10.17127/got/2019.18.010

\section{RESUMO}

As cidades brasileiras são caracterizadas por serem permeadas de contradições e problemáticas ligadas à sua dinâmica de ordenamento territorial, inerentes ao seu processo de formação histórica. Portanto, essa pesquisa tem como objetivo construir um referencial teórico sobre ordenamento territorial (OT), correlacionando-o com as experiências de ordenamento territorial urbano associadas a América Latina ( $A L)$ e ao Brasil. O percurso metodológico se deu por meio do levantamento teórico acerca dos principais conceitos ligados ao ordenamento territorial e as experiências de OT. A partir de então, pode-se verificar que os países da $\mathrm{AL}$ ainda apresentam muitas dificuldades no que diz respeito à implantação de políticas públicas, planos e legislações específicas para o ordenamento territorial. No Brasil, enquanto território latino-americano, se observa realidade semelhante. Palavras-chave: Ordenamento Territorial; Formação Histórica; América Latina; Brasil.

\section{ABSTRACT}

The Brazilian cities are characterized by being permeated with contradictions and problems related to their territorial planning dynamics, inherent to its updating process. Therefore, this research has as objective a theoretical reference on the territorial planning (OT), correlating them as territorial planning variables associated with Latin America (LA) and Brazil. The methodological positioning was given through the theoretical exercise on the 
main themes related to territorial planning and as OT experiences in the analyzed space. From then on, it can be verified that the countries of the LA still present many difficulties for the implementation of public policies, specific and specific for the land-use planning. In Brazil, as a Latin American territory, a similar reality is observed.

Keyword: Land Use Planning; Historical Formation; Latin America; Brazil.

\section{Introdução}

Atualmente, a população urbana no Brasil representa cerca de $84,36 \%$ do total (IBGE, 2010). Esse processo de urbanização se deu de maneira heterogênea no tempo e no espaço, sendo mais evidenciado a partir da década de 1950, mediante a necessidade de inserir o Brasil no mundo da globalização via projetos de modernização e industrialização, pautados principalmente nos espaços urbanizados (Dantas; Troleis; Morais, 2015). Outra forte característica da urbanização brasileira diz respeito às distintas formas de articulação entre as cidades, que variam de acordo com a dimensão econômica, cultural e até mesmo política (Sousa, 2013). Segundo Bezerra (2017), a urbanização contemporânea ocasionou muitas modificações no território brasileiro, a exemplo disso está o crescimento do número e o tamanho das cidades, bem como o aumento significativo dos papéis urbanos no cenário da divisão territorial do trabalho.

Segundo Dantas (2014), a cidade é a manifestação mais viva do que pode ser produzido, a partir da coexistência cooperativa humana, que é o permanente fluxo de relações sociais, políticas, econômicas e culturais, delimitadas pelos agentes sociais que permeiam os espaços urbanos. Dessa forma, elas podem ser comparadas a verdadeiros organismos vivos, nas quais a metamorfose do ambiente construído é constante e acelerada. As cidades do país apresentam em sua constituição um caráter mutável, permeado de contradições e diferentes problemáticas ligadas a sua dinâmica, como, impactos ambientais, carência de infraestrutura urbana, ocupação de áreas de alto risco, fragmentação socioespacial, entre outras que caracterizam uma ocupação descontínua e heterogênea e que são dialeticamente formadoras de seu ordenamento.

De acordo com Pérez (2014), muitos especialistas consideram o termo ordenamento territorial de significado complexo e polissêmico, que de maneira geral é empregado 
primordialmente em três facetas, são elas: ferramenta do planejamento; política pública; campo acadêmico.

O desenvolvimento do ordenamento territorial (OT) se dá em resposta à necessidade do planejamento urbano e do planejamento socioeconômico, ambas ações públicas (Pérez, 2014). Está, portanto, intrinsecamente ligado ao estabelecimento de normas, planejamento e planos. Para uma melhor delimitação do termo, essa pesquisa propõe a compreendê-lo conceitualmente e refletindo sobre a realidade latino-americana para que, por conseguinte, possamos compreender o significado dele na realidade brasileira.

Nesse contexto, essa pesquisa tem como objetivo construir um referencial teórico sobre ordenamento territorial urbano, correlacionando-os frente às experiências de ordenamento territorial associadas à realidade latino-americana e a brasileira.

Para tanto, adotou-se o levantamento bibliográfico para verificar o que os pesquisadores da área já produziram a respeito do tema, bem como respaldar as discussões desenvolvidas ao longo do texto (Appolinário, 2011). Para o entendimento do conceito de ordenamento territorial, tomou-se principalmente como base as contribuições de Ferrão (2011), Dasí (2008), Ferrão; Mourato (2015) e Sheid (2016). Enquanto isso, para o entendimento das experiências de OT na realidade da América Latina e do Brasil, fez-se uso dos estudos como o de Dantas (2014), Cortez-Yacila (2013), Cabeza (2002; 2012; 2016), Sabourin (2016) e Sousa (2013).

Dessa maneira, esse artigo apresenta mais 3 tópicos, além desse primeiro referente à introdução. O segundo, abordará uma conceituação de ordenamento territorial, o terceiro discutirá a temática frente as experiências latino americana e brasileira, o quarto apresenta as considerações finais.

\section{Conceituação de ordenamento territorial}

O surgimento do termo Ordenamento Territorial, conforme é compreendido atualmente, de significado multifacetado, aconteceu no continente europeu, porém ele não foi atribuído de maneira harmônica em todo seu território, passou por modificações, e evoluiu em termos e tempos distintos nos países (Souza, 2010). Para Ferrão (2011), os diversos sistemas e 
culturas de ordenamento territorial presentes na Europa são produtos dos enraizamentos políticos, institucionais e societais diferenciados. O autor (Id.) ressalta que a caracterização desses contrastes se torna mais evidente a partir do entendimento de duas expressões inglesas: land use planning, spatial planning.

A expressão land use planning diz respeito a ideia de que o ordenamento do território tem o principal objetivo de regular o uso e a transformação do solo, a partir de intervenções físicas e administrativas do Estado, que toma decisões baseadas no suporte técnico-racional de especialistas da área (Ferrão, 2011). Nessa perspectiva, o OT se torna um conjunto de atividades técnicas com objetivos políticos e necessariamente vinculados às questões técnicas, normativas e de zonamento territorial.

Porém, o conceito de OT vai além do planejamento e controle do uso do solo (HUANG, 2013). Acerca disso, a segunda expressão, spatial planning, mostra um entendimento de ordenamento territorial com enfoque mais amplo, estratégico integrado (Ferrão; 2011, Adams; Alden; Harris, 2016). Nessa perspectiva, Ferrão (2011), a interação e a colaboração entre os atores e a coordenação de diversas políticas territoriais e setoriais são elementos fundamentais para se promover uma agenda territorial de natureza prospectiva e de visão estratégica partilhada. Um exemplo disso está no trabalho de Kabish (2015) que utiliza a perspectiva do spatial planning voltado para a integração de serviço ecossistêmicos ao planejamento urbano. Contudo existe uma grande dificuldade em integrar as duas perspectivas nos modelos de planejamento (Couclelis, 2005).

De acordo com Sánchez (2007), a expressão ordenamento territorial, possui grande probabilidade de ter sido cunhada na legislação francesa no ano de 1944 por meio da expressão aménagement du territoire, com o intuito de integrar e regular o planejamento físico das questões socioeconômicas. Na França, conforme observa a autora (Id.), o OT começa a ser utilizado após a II Guerra Mundial com o objetivo de promover um planejamento econômico e amenizar os desequilíbrios regionais.

Retratando um pouco a Europa, enquanto um continente que avançou historicamente no debate do OT, é possível notar que o ordenamento territorial no contexto europeu passou por modificações ao passo que os países inseriram em suas gestões um processo de descentralização no qual diferentes níveis de autonomias foram adquiridos. A Carta 
Europeia do Ordenamento do Território CEOT, elaborada em 1983 e publicada em 1988, em Portugal, é um documento oficial relevante sobre o tema, nela o OT é definido como uma representação espacial das políticas nos âmbitos: econômico, social, cultural e ecológico da sociedade. Acerca dessa perspectiva o ordenamento pode promover um "disciplinamento" do uso do território ao passo em que visa amenizar os conflitos presentes nas diferentes ações públicas e privadas (Figueiredo, et al, 2005).

A Carta Europeia (1988) defende ainda que o ordenamento territorial tem como objetivo base proporcionar melhoria para a qualidade de vida da população dentro do espaço que foi planejado para o desenvolvimento de suas atividades. Para o alcance desse objetivo, 0 documento alerta que O OT deve partir dos princípios de democracia, integração, funcionalidade e prospectividade, visto que deve, respectivamente: garantir a participação da população e dos seus representantes políticos; integrar as políticas setoriais; considerar as especificações regionais; e ser capaz de observar o desenvolvimento a longo prazo.

Segundo Dasí (2008), o ordenamento do território é uma área muito sensível no contexto da União Europeia, pois não há premissas para a produção de uma suposta Direção Europeia de Ordenação Territorial, tampouco a possibilidade de homogeneização dos estilos de planejamento territorial entre os seus países. Dessa forma, o ordenamento territorial não assume um perfil ligado a nenhum dos Estados europeus visto que cada país possui sua cultura, ou seja, sua forma de pensar o planejamento e o ordenamento territoriais. De acordo com a carta, o ordenamento deve levar em consideração a presença de múltiplos fatores decisivos, sendo eles individuais e institucionais, que irão interferir diretamente no cenário socioeconômico, administrativo e ambiental.

A carta reafirma que o OT é concomitantemente um ramo de investigação científica e acadêmica, um instrumento de planejamento e uma política pública. Logo, pode-se notar que a CEOT teve o intuito de mostrar que o ordenamento do território não se limita exclusivamente a um termo jurídico, mas como uma instância multidisciplinar. Em sua primeira faceta, a científica, o OT estuda os efeitos e transformações produzidos no território pelas constantes atividades humanas (Pérez, 2014). Para Becker (2005) o caráter científico do OT é notado quando incorpora métodos que permitem analisar e modelar o território, adquirindo um perfil interdisciplinar que tem como aplicabilidade prática o planejamento do território. Essa característica é evidenciada por Alves (2014) quando 
observa a fixação dessa temática enquanto importante ramo acadêmico, o qual necessita da formação de profissionais de áreas diversas como geógrafos, engenheiros e arquitetos.

A segunda faceta, a de instrumento de planejamento, Pérez (2014) a descreve como sendo uma técnica ou metodologia de atuação, na qual se dá a distribuição dos usos do território, bem como da coordenação das competências dadas as suas respectivas instâncias administrativas. Nos países europeus, são os Planos de Ordenamento do Território que se configuram como principal materialização dessa faceta do ordenamento territorial. Existem ainda outros instrumentos como a avaliação de impacto territorial dos projetos não previsto no planejamento, os acordos ou contratos intermunicipais de ordenamento do território e urbanismo, bem como outros instrumentos informais de caráter voluntário e jurídico, os quais são baseados nos paradigmas de governança, respaldada principalmente na cooperação e participação (Scheid, 2016).

Enquanto terceira faceta, a política pública de intervenção no território, o OT depende do processo histórico, do espaço e da cultura que se desenvolve (Pérez, 2014). Scheid (2016) considera o ordenamento territorial sob a perspectiva de política pública, capaz de possibilitar o planejamento físicos de áreas compreendidas nas instâncias que englobam territorialmente um ou vários municípios, como acontece com as áreas metropolitanas, comarcas, províncias e sub-regiões, desenvolvendo-as mediante os sistemas: da cidade, de articulação territorial e de espaços livres. O autor ressalta também que o OT refere-se também ao ordenamento básico do uso do solo e tem como finalidade permitir coordenação, compatibilidade e equilíbrio entre as atividades humanas de tal forma que a longo prazo elas possam se consolidar dentro de um modelo de uso racional do território, respondendo aos objetivos bases (sustentabilidade, coesão territorial e solidariedade).

Logo, a Carta propõe linhas mestras de ordenamento territorial, que contribuem em uma melhor organização do território europeu, com importantes definições para outros espaços, na busca de soluções para seus problemas, que ao superar o âmbito nacional auxilia na criação de um sentimento de unidade comum para a Europa (Pérez, 2014).

A partir de então, pode-se notar que a realidade europeia conta com significativos avanços em termos de instrumentos e de avanços teórico-conceituais sobre o ordenamento territorial. Apesar de não haver uma homogeneização entre as políticas de ordenamento 
territorial dos seus países, existem diretrizes gerais sob as quais as políticas nacionais são elaboradas. Concomitante a isso, a Europa encontra-se em um nível avançado de desenvolvimento econômico que pode ser justificado principalmente, entre muitos outros fatores, pela sua própria formação histórica, a qual conta com civilizações mais antigas que as de outros espaços. A exemplo disso está a América Latina, que foi colonizada pelas nações europeias, predominantemente por meio das colônias de exploração, o que ratifica ainda mais as desigualdades entre esses territórios. Tais circunstâncias geraram um território heterogêneo e amplamente caracterizado desigualdades, que se reverberam ao longo da história e que até hoje ainda não foram superadas.

\section{Ordenamento Territorial, a realidade latino-americana e brasileira}

A América Latina é marcada por grandes desigualdades ao longo de seu território, pobreza, concentração dos meios de produção e muitas diferenciações a nível de desenvolvimento econômico e social nas diversas regiões de um mesmo país (DANTAS, 2014). Esse contexto, é fruto de todo um processo histórico de colonização perversa por exploração. Há poucos espaços que concentram uma grande parte da população e da produção em detrimento de grande número de regiões dispersas espacialmente, baixo povoamento e com baixa representação econômica. Isso faz com que se tenham lugares onde a população desfruta de uma melhor qualidade de vida, semelhante àquela vivenciada nos países desenvolvidos, e outros nos quais essa qualidade de vida é muito inferior (CEPAL, 2012).

Mediante esse contexto, Cortez-Yacila (2013) comenta que os processos de segregação e de auto-segregação levam ao surgimento de lugares planejados, com projetos arquitetônicos proeminentes, nos quais a população não chega a imaginar a existência de espaços mais pobres na cidade, enquanto que por outro lado, se ressalta a miséria e a corrupção.

No Brasil, enquanto país latino-americano, o enfoque das políticas públicas para o ordenamento territorial se deu a partir de um período muito recente da história do país, diferentemente do que aconteceu com países desenvolvidos, onde essa preocupação aconteceu há mais tempo, conforme mostram as pesquisas para os países europeus (Ferrão, 2011; Souza, 2010; Sheid, 2016). 
Segundo Lima (2015), no caso brasileiro, a inserção do território na elaboração de políticas é resultado de engajamento social e militância dos diferentes profissionais da área. Assim, o autor conceitua o ordenamento territorial como "[...] uma interação de forças que visa conciliar políticas específicas, com o uso equilibrado de recursos e a ocupação do espaço, com foco no desenvolvimento sustentável passível de avaliação." (Lima, 2015, p.69).

Nesse sentido, é importante destacar que no planejamento territorial são promovidas todas as ações que se desdobram em ordenamento territorial e envolve diferentes agentes. Isso porque o OT constitui-se como um ciclo de articulação entre o Estado/Governo e a Sociedade/Instituições, no qual se elabora diagnósticos, pesquisas, formulações, validações, capacitações e implementação (Figueiredo, et al, 2005). Segundo Arruda (2013), a interação entre os diferentes atores, pertencentes aos vários níveis e escala, de maneira integrada é capaz de promover a gestão territorial, que formula o planejamento territorial, e este por sua vez promove o ordenamento territorial. A Figura 1 esquematiza esses processos.

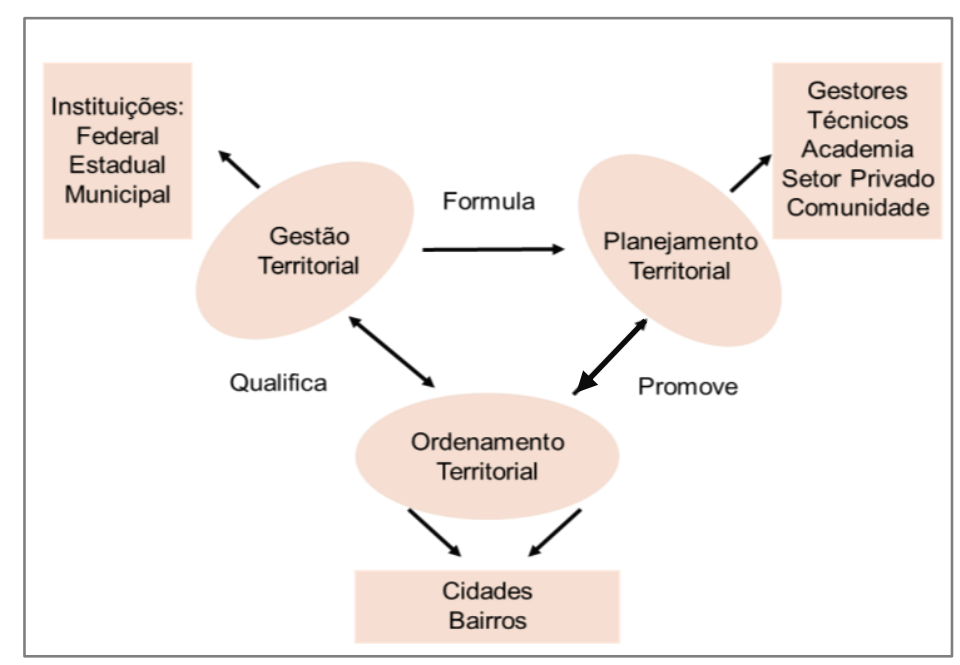

Fig. 1 - Elementos e agentes remodeladores do espaço.

Fonte: Arruda, 2013.

Na Figura 1, ressalta-se ainda que para se ter uma gestão territorial em excelência o enfoque deve perpassar pela escala municipal, pois para atender as necessidades do ordenamento territorial se faz necessário observar as especificidades de cada cidade envolvida. Para tanto, a compreensão da relação existente entre ação, espaço e território é muito importante. Acerca disso, Costa (2012) parte do entendimento de espaço enquanto uma relação social múltipla e complexa, que reflete o modo de organização da sociedade e a forma que direciona suas ações, para chegar ao conceito de território, afirmando que: "se 
o espaço implica na relação geral dos homens entre si, na sua unicidade e multiplicidade, o território é a materialidade dessa relação, nas formas de uso expressas espacialmente como base concreta." (Costa, 2012, p. 18).

Vale ressaltar que, em termos de ordenamento territorial, diversos estudos ligados que o analisam para o contexto de Europa e América Latina destacam o papel do Estado enquanto ente maior de regulação do uso e ocupação do espaço, criação de políticas públicas e instrumentos que estejam voltados para o enfoque do território (Pérez, 2014), (Scheid, 2016), (Cabeza, 2016). Segundo Moraes (2005) o território é um espaço de exercício de poder, o qual está centralizado no Estado, e complementa sua discussão afirmando:

O grande agente da produção do espaço é o Estado, por meio de suas políticas territoriais. É ele o dotador dos grandes equipamentos e das infraestruturas, o construtor dos grandes sistemas de engenharia, o guardião do patrimônio natural e o gestor dos fundos territoriais. Por estas atuações, o Estado é também o grande indutor da ocupação do território, um mediador essencial, no mundo moderno, das relações sociedade-espaço e sociedade-natureza (MORAES, 2005, p.43).

Diante disso, o ordenamento territorial promovido pelo Estado, através de suas ações públicas, leva para os locais onde efetuam suas ações elementos característicos, apesar de estar permeado por entendimentos genéricos baseado em modelos padrões de planejar o território (Alves, 2014). Essa importância do Estado é percebida na realidade brasileira, conforme mostra a história.

Segundo Cabeza (2016), nos países da América Latina, o OT possui quatro objetivos centrais:

a) resolver ou prevenir conflitos de uso das terras urbanas, suburbanas e rurais a partir de uma perspectiva de planejamento físico espacial; b) promover a utilização sustentável dos recursos naturais, a conservação da biodiversidade e a proteção do meio ambiente para garantir o crescimento econômico e habitabilidade dos territórios a partir de uma perspectiva de uma perspectiva de desenvolvimento sustentável; c) reduzir ou evitar a ocorrência de catástrofes causadas pelo uso e ocupação inadequada dos territórios desde uma perspectiva de gestão de risco e/ ou adaptação às alterações climáticas; e d) resolver os desequilíbrios do desenvolvimento econômico regional e a fragmentação territorial produzida pela lógica espacial dos modelos econômicos implementados, a partir de uma perspectiva de desenvolvimento territorial integrado" (CABEZA, 2016, p. 70). (tradução nossa) $^{48}$.

\footnotetext{
${ }^{48}[\ldots]$ a) Resolver o prevenir conflictos de uso de las tierras urbanas, suburbanas y rurales desde una perspectiva de planificación física espacial; b) Propiciar el aprovechamiento sostenible de los recursos naturales, la conservación de la biodiversidad y la protección del ambiente para garantizar el crecimiento económico o la habitabilidad de los territorios desde una perspectiva de desarrollo sostenible; c) Reducir o evitar la ocurrencia de catástrofes por uso u ocupación inadecuada de los territorios desde una perspectiva de gestión del riesgo y/o adaptación al cambio climático; y, d) Resolver los desequilibrios del desarrollo económico regional y la fragmentación territorial producidos por la lógica espacial de los modelos económicos implementados, desde una perspectiva de desarrollo territorial integral. (CABEZA, 2016, p. 70)
} 
Diante disso, o referido autor (Id.) observa que o alcance desses objetivos expressam duas perspectivas para o ordenamento territorial, uma delas é passiva e outra ativa. A visão passiva está respaldada na regulamentação física e espacial do uso e ocupação do solo, para escalas locais, ou seja, dentro da esfera do município. Enquanto isso, a visão ativa se baseia em instrumentos de intervenção territorial, com escalas a níveis regionais e nacionais a partir de princípios setoriais. No que se refere as políticas territoriais latino-americanas, Sabourin (2016) comenta que é comum elas tentarem associar muitos objetivos e enfoques inovadores, porém eles nem sempre se combinam entre si, o que fragiliza e põem em contradição esses instrumentos.

Antes do surgimento de políticas públicas propriamente caracterizadas como sendo de ordenamento territorial, os países latino-americanos tiveram experiências com diversas opções de planejamento, podendo ser setoriais e multissetoriais. De acordo com CortezYacila (2013), o planejamento territorial tomou forma mediante as conjunturas dos diferentes países da América Latina a partir de modelos adaptados da experiência europeia. Cabeza (2002) mostrou em seu estudo sobre o desenvolvimento do ordenamento territorial uma escala de tempo a variação de tais políticas, conforme mostra a Figura 2.

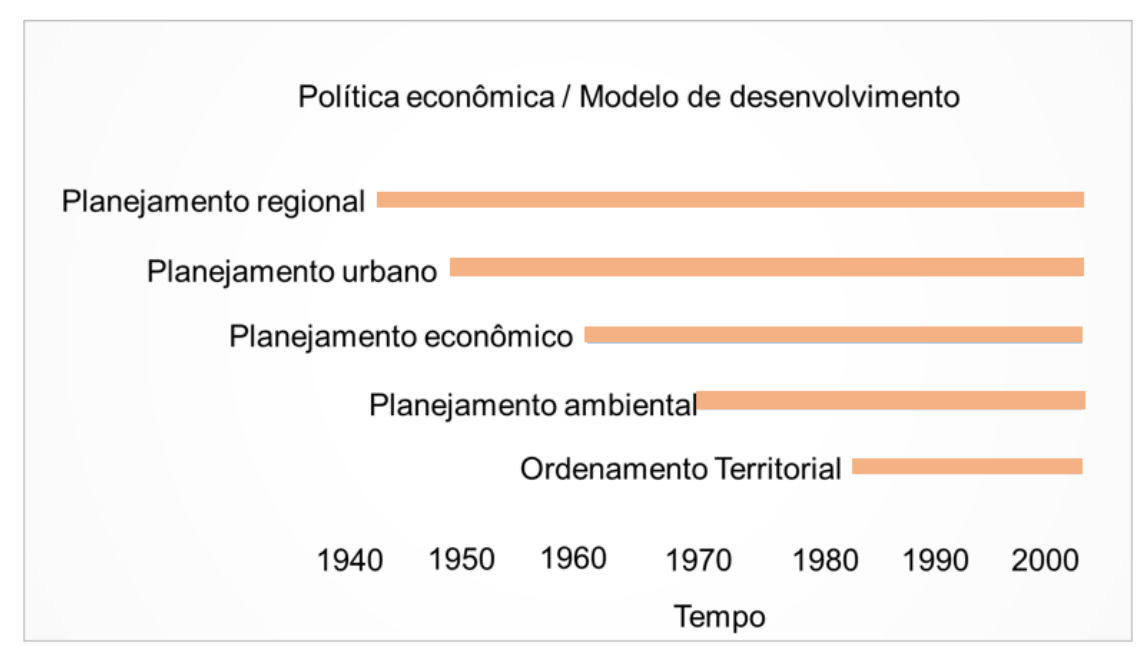

Fig. 2 - Políticas econômicas ou modelos de desenvolvimento, de 1940 a 2000.

Fonte: Cabeza, 2002.

A partir da leitura da Figura 2, pode-se notar que na década de 1940 dá-se início a aplicação de políticas de planejamento regional no ocidente, que segundo Cabeza (2002), em virtude do fato de se deterem a resolver problemas setoriais se distanciavam da visão global, característica do OT e, por isso, não se configuravam ainda como tal. Em estudo mais 
recente, Cabeza (2012) quando discute sobre ordenamento territorial para a América Latina elenca cinco elementos chaves: o planejamento do uso do solo urbano, o ordenamento territorial, a descentralização e o desenvolvimento territorial.

As primeiras estratégias foram elaboradas visando o ordenamento das bacias hidrográficas, de acordo com Cabeza (2002). Os países que desenvolveram algo nesse sentido foram: Peru, México, Uruguai, Colômbia e o Brasil, este último com a criação da Comissão do Valle do São Francisco.

Entre as décadas de 1950 e 1960 há destaque para políticas de planejamento urbano e econômico, as quais foram embasadas pelo modelo econômico de industrialização. Nessa configuração, o Estado detinha o papel principal no que se refere a promoção de infraestrutura e amenização das desigualdades regionais. Essas medidas eram empregadas de maneira desigual ao longo do território dos países, de tal maneira que aos poucos os países deixaram de ser rurais e se tornaram urbanos, porém com uma concentração de polos urbanos, localizados em poucas regiões, em detrimento de uma grande dispersão de áreas que praticamente não receberam investimentos (Cabeza, 2012).

Enquanto isso, o Brasil também tinha o processo de urbanização se tornando mais evidente entre as décadas de 1940 e 1950, período em que houve um grande fluxo de migração do campo para as cidades sem haver, contudo, uma adequada disposição do espaço urbano. Tal processo recebeu fortes influências da globalização e acompanhou o período de industrialização, chegando ao ápice de êxodo rural em 1970 (Lima, 2015).

Nos anos 1970 houve, na América-Latina, uma predominância do tipo de ordenamento "pacífico", com ênfase urbanística (Cabeza, 2016). Foram criadas normas para orientar o crescimento das cidades, que não deixavam de ser apenas regulamentações que não contemplavam o sentido completo de ordenamento territorial (Cabeza, 2012).

De acordo com Cortez-Yacila (2013), entre as décadas de 1950, 1960 e 1970 foram elaborados muitos documentos técnicos chamados de "planos de desenvolvimento territorial", os quais atuavam de acordo com a visão dominante da época, a keynesiana, que defende a intervenção estatal na economia e na sociedade com o intuito de alcançar o pleno emprego, por meio do paradigma desenvolvimentista vivenciado em alguns países latino-americanos, a saber: Argentina, Brasil, Chile e México. Vale ressaltar que nesse 
período a América Latina vivenciou um período de ditaduras militares, as quais tiveram como principais pontos em comum a "[...] dissolução das instituições representativas, falência ou crise aguda dos regimes e partidos políticos tradicionais, militarização da vida política e social em geral" (Coggiola, 2001, p.11).

Outro ponto importante, observado por Coggiola (2001), é que as ditaduras da década de 1960 assumiram um caráter "preventivo" de um suposto contágio com a Revolução Cubana e tiveram muita influência da diplomacia estadunidense diante de um cenário de tensão internacional entre os Estados Unidos e a União das Repúblicas Socialistas Soviéticas (URSS), denotando assim a dominação do capitalismo sobre os países periféricos, porquanto, as ditaduras de 1970 adquiriram um caráter contra-revolucionário, pois conforme afirma Diniz (2015), a década de 1970 ficou marcada por muitas mudanças, revoluções de libertação nacional, ditaduras e crises estruturais no centro da periferia capitalista, essa crise no sistema se deu principalmente pelo esgotamento do modelo de produção fordista que dominou o modelo produtivo no início do século XX.

Nesse contexto, parte do sistema de planejamento nacional era liderado por instituições nacionais de planejamento, que muitas vezes eram inoperantes e burocratizadas, visto que buscavam concentrar a atenção para os grandes centros urbanos, mormente para as capitais dos estados, muito embora tenha ocorrido já na década de 1970 as primeiras políticas públicas de desconcentração e fomento a novos centros urbanos (França, et al., 2009). Isso provocou o despovoamento de grandes áreas dispersas pelos países, as quais detinham de uma baixa produtividade econômica em virtude do pouca ou nula destinação de investimentos para esses espaços, o que acentuou as desigualdades regionais, principalmente entre as regiões metropolitanas e as áreas não metropolitanas dessas nações.

No Brasil, durante o governo de João Goulart, 1961 a 1964, houve as primeiras articulações no sentido de promoção das chamadas "reformas de base" como proposta a novas saídas para o desenvolvimento do Brasil (Lima, 2015). Porém tais mudanças foram suspensas em virtude do período de Ditadura Militar, compreendido entre 1964 e 1985. De acordo com Sant'Ana, Fava; Bueno (2010) foi um momento pautado na burocracia, na tecnocracia e no milagre econômico. Nesse contexto, os autores relatam que os planos diretores elaborados eram instrumentos de controle do Estado sobre os municípios e foram norteados pela visão 
de que o planejamento tem a função de manter o regime político e o sistema econômico com o qual estava associado. Tal experiência caracteriza o chamado ordenamento "pacífico" vivenciado, no mesmo período, no contexto latino-americano (Cabeza, 2016).

Tal concepção distancia os planos diretores elaborados na época dos princípios que regem o entendimento de instrumento de planejamento voltado para o ordenamento territorial. Haja visto que as primeiras técnicas de planejamento utilizadas eram baseadas na visão tecnocrata, sem participação popular, na qual o espaço era tido como uma variável autónoma e isolada (Carvalho et al., 2016). Isso tira do planejamento urbano a colagem no território e a importância da compreensão de suas particularidades para a elaboração de planos eficazes e eficientes. Conforme Moraes (2005), embora se objetivasse a integração nacional, as teorias da centralidade tinham maior concordância com a perspectiva tecnocrata vigente, se opondo tanto da visão aménagement du territoire quanto da spatial planning, ambas prospectivas, e dando espaço para a ciência-regional norte americana e a geografia quantitativa. $\mathrm{O}$ autor ressalta também que houve um desprendimento na política econômica da ótica espacial o que contribuiu para a crise do planejamento territorial brasileiro.

Entre as décadas de 1970 e 1980 se desencadeou na América Latina, uma série de questionamentos acerca da concentração de poder no Estado nacional, paralelamente a isso se deram muitas mudanças nos planos econômicos (Fisher, 2014). Tal contexto favoreceu a tomada de força dos movimentos de descentralização na década de 1980, os quais estavam associados a uma economia de mercado que necessitava de estratégias diferentes de gestão territorial e que vieram a melhorar a eficiência do Estado (Cabeza, 2012). Segundo Sabourin (2016), ao considerar que a territorialização consista na aproximação entre as tomadas de decisão e os problemas dos usuários, é inevitável que esse processo passe pela desconcentração do Estado a partir da descentralização e participação popular.

No final da década de 1980, o Brasil tem como plano de fundo na redemocratização do país, de descentralização e de ganho de autonomias (Lima, 2015; Cabeza, 2012). Esse momento de desconcentração do Estado foi muito importante para o avanço da democracia nos países latino americanos. No entanto, paralelamente a isso, entra em cena a agenda neoliberal, que priorizava os localismos, ao invés dos regionalismos ou planejamentos 
macros, que são estes últimos fundamentais para o OT. Ao estudar as contradições da década de 1990 no Brasil, Klink (2013) observa que essa tendência de reorganizar a atuação do Estado para o local desencadeou uma série de estratégias e práticas espaciais baseadas em uma guerra tributária e desregulamentação competitiva entre os estados e municípios com o objetivo de atrair novos empreendimentos. Além disso, nesse contexto, vivia-se no Brasil um crescimento significativo de novos municípios e o desafio de se ter o mínimo de coordenação e planejamento entre as cidades nos aglomerados urbanos e em regiões metropolitanas (Klink, 2013).

A preocupação com o tema do ordenamento territorial, foi efetivamente tratado na Constituição Federal de 1988, no ápice da volta à democracia. Tal enfoque foi inspirado nos "planos de ordenação do território", de forma análoga as experiências já em curso na Europa (Galvão, 2005). Assim, a Constituição Federal (1988) em seu Art. 21, inciso IX, determina que "elaborar e executar planos nacionais e regionais de ordenação do território e de desenvolvimento econômico e social" é uma das competências da União.

Porém, vale ressaltar que o processo de descentralização e tomadas de autonomia até os dias atuais são insuficientes, pois há uma descentralização de funções sem o devido respaldo financeiro. Associado a isso é comum a corrupção no manejo dos recursos financeiros pelas entidades territoriais (Cabeza, 2012).

Para Sabourin (2016), o que realmente acontece é um tipo de adaptação dentro de seu próprio marco constitucional e mediante as instituições já existentes. Para exemplificar essa relação, o autor (Id.) ressalta que existe sempre um Ministério do Planejamento, como é o caso da Argentina, do Interior, no Chile, da Integração Nacional, no Brasil, ou do Ordenamento Territorial, no Uruguai, que são responsáveis pela planificação e coordenação território. Há também uma gama de outros dispositivos jurídicos e de instituições para promover a descentralização e regionalização no ordenamento do território, os quais Sabourin (2016) destaca que podem funcionar bem, sem necessariamente recorrerem a participação popular, em virtude de já terem sido previamente eleitos democraticamente em eleições locais e regionais, sendo portanto representantes conhecedores da realidades dessas localidades, e por isso com maior probabilidade para a tomada de decisões com maior colagem no território. 
No tocante às políticas de planejamento ambiental na América Latina, elas começaram a ganhar força entre os anos de 1970 e 1980, com focos no ordenamento ecológico ou ambiental, zonamento ecológico-econômico, as quais se tornam mais concretas no final da última década do século $X X$, a partir da criação de leis e ministérios específicos com o objetivo de proteger os seus respectivos patrimônios culturais, como se deu no: Uruguai, Bolívia, Colômbia, Costa Rica, Equador, Cuba, El Salvador e no Panamá (Cabeza, 2016).

Em 2000, dá-se início ao tipo de ordenamento ativo, baseado em políticas de ordenamento dos sistemas urbanos a níveis nacional e regional. Outra presença forte é a de políticas que objetivavam o desenvolvimento econômico a partir do territorial, com grande marco no desenvolvimento sustentável. A sustentabilidade ganhou espaço jurídico, através da criação de leis no Uruguai, Equador e em El Salvador. (Cabeza, 2016)

Porém, no contexto da globalização, respaldada pela doutrina neoliberal, não há espaço para solidariedade e conduz a modelos vigentes a serem contraditórios aos princípios de sustentabilidade (Sousa, 2014). Diante disso, a partir das reflexões de Cabeza (2016), bem como pelo histórico de países ex-colônias que atualmente são de capitalismo periférico como o Brasil, pode-se afirmar que hoje o território da América Latina é palco de governança para políticas promovidas por interesses transnacionais, que são apoiadas por grupos econômicos nacionais e por governos locais. Nesse sentido, boa parte das políticas desenvolvidas é alheia ao território em que são empregadas, causando impactos socioterritoriais e gerando constantes conflitos, entre os grupos sociais (principalmente entre aqueles dominantes do capital) na luta pelo controle dos diferentes tipos de territórios (Sousa, 2014). O perfil dos enfoques das políticas de ordenamento territorial fora espacializado na Figura 3. 


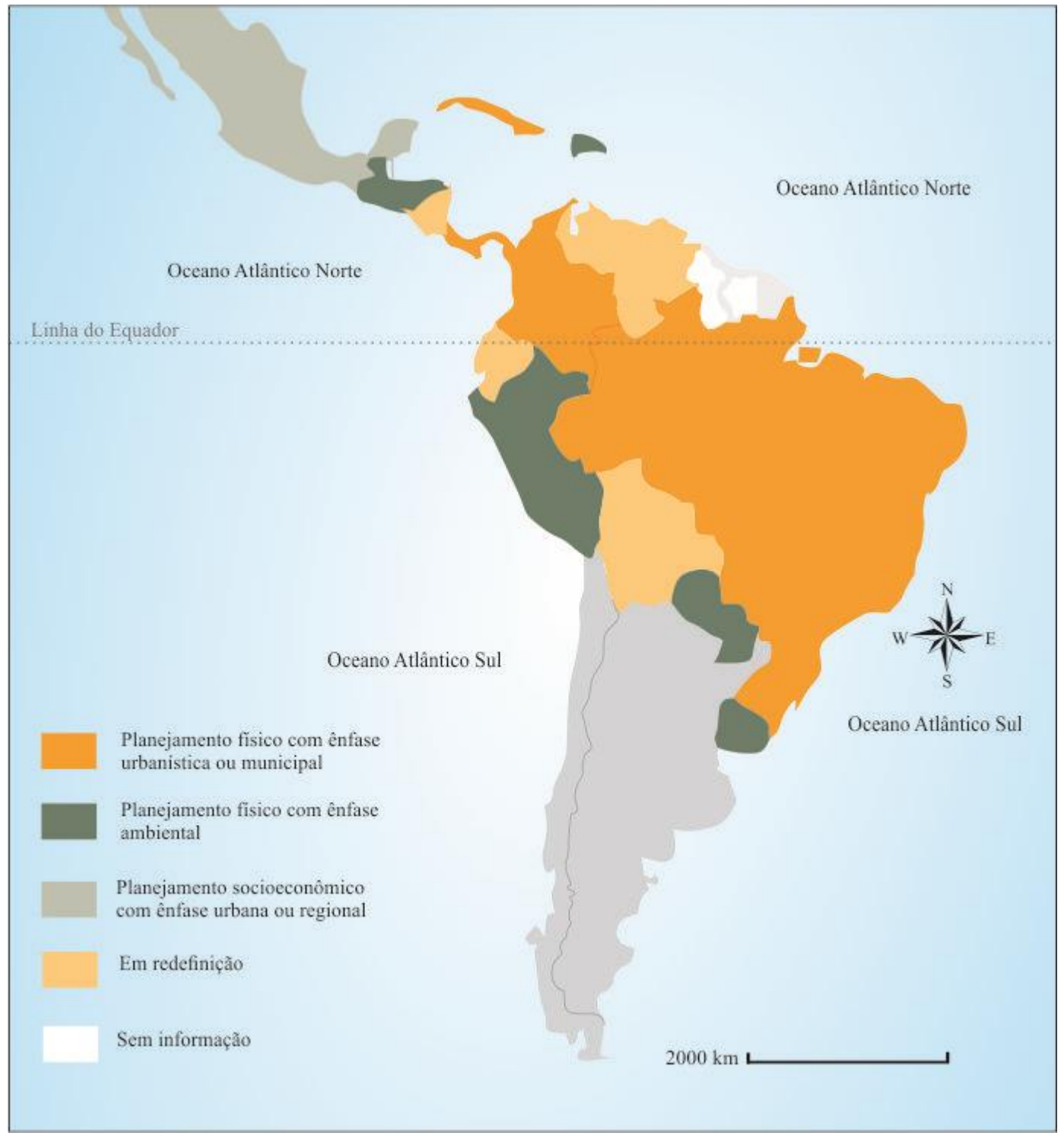

Fig. 3 - Enfoques das políticas de ordenamento territorial na América Latina - 2011.

Fonte: Cabeza, 2012.

Para complementar a discussão, o autor aponta que existe uma certa deficiência das políticas de ordenamento territorial nos países latino americanos no que se refere aos fundamentos legais, mais restritamente na existência de leis específicas de ordenamento territorial que norteiem essas políticas. Ao comparar a realidade de OT da América Latina com a da Europa, Cabeza (2012) verifica que neste continente as políticas de ordenamento territorial possuem legislações específicas para a temática e que há uma maior valorização das instituições para inserir nas políticas públicas de seus países o enfoque do território.

Hoje, para o contexto brasileiro, após mais de 30 anos da promulgação da Constituição Federal, existe uma significativa quantidade e diversificação de leis, projetos, planos e instrumentos que foram elaborados de maneira isolada e muitos são discordantes entre si, 
pertencendo a esfera de atuação ora da União, ora dos Estados e ora dos Municípios. Porém, ainda não se tem no país um sistema em nível nacional que seja capaz de integrar e promover a hierarquização de uma ação coordenada das ações públicas do Estado em seus diferentes níveis de governo. Isso acontece em virtude do contexto no qual as decisões políticas dos gestores que compõem o Estado estão a favor de seus interesses, os quais atendem a um objetivo maior que é a de acumulação do capital, por meio da reconcentração e não distribuição de oportunidades perante o vasto território brasileiro. Tal é a realidade que, no Brasil, a agenda política para a promulgação da Política Nacional de Ordenamento Territorial (PNOT) nunca ganhou força por parte das elites políticas locais, que são representantes das áreas historicamente concentradoras e privilegiadas de investimentos, apesar da tentativa de inserir essa agenda por parte de governos populares que estiveram no poder no país. Dessa forma, para que tal propósito seja alcançado com maior êxito, se faz necessário manter as estruturas de fragmentação e desigualdade, o que contradiz aos postulados teóricos de ordenamento territorial.

A Tabela 1 reúne as principais leis que estão ligadas ao ordenamento territorial no Brasil. 
Tabela 1 - Principais leis brasileiras que estão ligadas ao ordenamento territorial.

\begin{tabular}{|c|c|}
\hline Lei & Conteúdo \\
\hline $\begin{array}{l}\text { Lei № } 6.015 \text {, de } \\
31 \text { de dezembro } \\
\text { de } 1973\end{array}$ & Dispõe sobre registros públicos e dá outras providências \\
\hline $\begin{array}{l}\text { Lei № } 6.766 \text {, de } \\
19 \text { de dezembro } \\
\text { de } 1979\end{array}$ & Dispõe sobre o parcelamento do solo urbano \\
\hline $\begin{array}{l}\text { Lei № } 6.938 \text {, de } \\
31 \text { de agosto de } \\
1981\end{array}$ & $\begin{array}{l}\text { Dispõe sobre a Política Nacional do Meio Ambiente, seus fins e mecanismos de } \\
\text { formulação e aplicação, e dá outras providências. }\end{array}$ \\
\hline $\begin{array}{l}\text { Lei № 9.433, de } \\
08 \text { de janeiro de } \\
1997\end{array}$ & Institui a Política Nacional de Recursos Hídricos \\
\hline $\begin{array}{l}\text { Lei № } 7.661 \text {, de } \\
16 \text { de maio de } \\
1998\end{array}$ & Institui o Plano Nacional de Gerenciamento Costeiro - PNGC \\
\hline $\begin{array}{l}\text { Lei № } 10.257 \text {, de } \\
\text { julho de } 2001\end{array}$ & Estabelece diretrizes gerais para a Política Urbana (Estatuto da Cidade) \\
\hline $\begin{array}{l}\text { Lei № } 11.977- \\
2009 \text {, de } 07 \text { de } \\
\text { julho de } 2009\end{array}$ & $\begin{array}{l}\text { Dispõe sobre o Programa Minha Casa, Minha Vida - PMCMV e a regularização } \\
\text { fundiária de assentamentos localizados em áreas urbanas, e dá outras } \\
\text { providências. }\end{array}$ \\
\hline $\begin{array}{l}\text { LEI № } 13.089 \text {, de } \\
12 \text { de janeiro de } \\
2015 .\end{array}$ & $\begin{array}{l}\text { Institui o Estatuto da Metrópole, altera a Lei no } 10.257 \text {, de } 10 \text { de julho de 2001, e } \\
\text { dá outras providências. }\end{array}$ \\
\hline $\begin{array}{l}\text { Lei № } 13.465 \text { - } \\
2017 \text {, de } 11 \text { de } \\
\text { julho de } 2017\end{array}$ & $\begin{array}{l}\text { Dispõe sobre a regularização fundiária rural e urbana, sobre a liquidação de } \\
\text { créditos concedidos aos assentados da reforma agrária e sobre a regularização } \\
\text { fundiária no âmbito da Amazônia Legal; institui mecanismos para aprimorar a } \\
\text { eficiência dos procedimentos de alienação de imóveis da União, e dá outras } \\
\text { providências. }\end{array}$ \\
\hline
\end{tabular}

Fonte: adaptado de Poletto, 2008.

Diante disso, nota-se que algumas legislações têm um enfoque urbano e outras o ecológico ambiental, semelhante aos observado por Cabeza $(2012 ; 2016)$ em sua pesquisa panorâmica da América Latina. Segundo Poletto (2008), a tendência das políticas territoriais é a fragmentação, que representa uma maior especialização dos aparelhos do Estado bem como à setorização dos planos, programas e projetos. Essa realidade faz com eles tenham suas forças diminuídas frente as mais diversas demandas divergentes originadas nos grandes fluxos de capitais, bens, serviços e informações. Poletto (2008) reflete ainda que tal contexto contribui para uma ineficácia das macropolíticas, como é o caso dos "[...] programas nacionais de "zonamento ecológico-econômico", as "políticas nacionais integradas" ou os "planos nacionais de desenvolvimento", a exemplo da recente experiência 
dos "eixos nacionais de desenvolvimento" (Cabeza, 2008, p. 60). Outro ponto a ser observado é a tomada de autonomia dos municípios pautada nessas legislações, notadamente exemplificada pelo Estatuto da Cidade - Lei 10.257 (2001). Isso representa o processo de descentralização observado tanto para os países europeus (Pérez, 2014), quanto para os latino americanos.

Em 2003, foi iniciado a elaboração da Lei Política Nacional de Ordenamento Territorial (PNOT) por coordenação do Ministério de Integração Nacional. Nesse processo, Rückert (2007) enfatiza que a Secretaria de Políticas de Desenvolvimento Regional executou algumas ações nesse sentido, dentre elas estão as oficinas e seminários nacionais, bem como o apoio a estudos sistemáticos que embasem a formulação da política. Porém o autor supracitado conclui a sua pesquisa observando que não existe um debate nacional instaurado acerca da PNOT, ela está restrita ao meio acadêmico. Além de estar atrasada em seu processo de elaboração, segundo o autor, encontra-se também em descompasso com os principais debates de políticas territoriais a contexto internacional.

A problemática ligada a dificuldade de elaboração e execução de instrumentos de ordenamento territorial presente no Brasil reflete o que Cabeza (2012) observa para os países da América Latina, em que é necessária uma forte pressão do Estado nacional para colocar em prática essas normas, visto que as políticas territoriais tocam em interesses contraditórios, gerando muitos conflitos. Continuando com o autor, na cultura latinoamericana, as leis por si só não são satisfatórias, pois existe uma grande tendência a sua violação por meio de mecanismos diversos, que trazem em torno de si os interesses do capital, que se coadunam com representações políticas locais para fins de defesa de seus interesses. Isso faz com que sejam necessárias modificações não apenas nos marcos legais, mas também uma profunda mudança na cultura política e atual governança, cabendo à sociedade a proeminência na luta reivindicatória em defesa dos direitos do território.

\section{Considerações Finais}

Mediante tal discussão, pode-se observar que atualmente os países latino-americanos ainda enfrentam muitas dificuldades no que diz respeito à implantação de políticas públicas, planos e legislações específicas para o ordenamento territorial. Isso pode ser justificado 
pelas desarticulações entre as políticas territoriais e setoriais bem como entre o desenvolvimento socioeconômico, ambiental e territorial. Além disso, tem-se uma predominância da visão setorial sobre a territorial, pois as políticas e programas são criados, evidencialmente, com base nos diversos setores isoladamente como o caso do econômico, educacional e habitacional não dando ênfase às particularidades do território. Analogamente a isso estão as decisões nacionais sobrepondo-se às regionais e locais, dado que apesar de se ter conseguido um certo grau de descentralização as unidades regionais e locais ainda se encontram despreparadas em várias instâncias para executar as funções que Ihes cabe. Soma-se a esse contexto uma forte inconsistência da gestão territorial que ainda predomina uma visão tecnocrata e impositiva com relação a democrática. Outros fatores importantes como: corrupção, ausência de vontade política para destinar recursos financeiros a execução dos planos de OT, bem como a descontinuidade de projetos entre os governos, que continuamente isolam o que a gestão passada realizou para recomeçar em projetos de seus governos (Cabeza, 2012; 2016).

Todo esse contexto se reflete no território latino-americano, fruto da construção social, uma crescente diferenciação econômica e social que pode ser observada na grande quantidade de bolsões de pobreza e marginalização associadas a exclusão. Para Sousa (2014), essa desigualdade territorial é consequência das dinâmicas territoriais promovidas por políticas públicas e de gestão territorial geradas na América Latina mediante um contexto neoliberal, assim como também a permanência da condição de colônia ou periferia dos países imperialistas colonizadores. Isso faz com se tenha uma imprescindível necessidade de se atuar frente à desigualdade e marginalização nos programas de desenvolvimento territorial.

A partir de então, nota-se que o Brasil, enquanto território da América Latina, possui em seu processo de urbanização e ordenamento territorial elementos muito semelhantes àqueles apontados para os demais países da região. Dessa forma, a inserção de novos instrumentos de ordenamento territorial é fundamental para possibilitar resolução de problemas urbanos, como o da irregularidade fundiária, visto que a partir de então, se pressupões que a gestão da cidade passa a acontecer mediante os princípios de democracia, integração, funcionalidade e prospectividade. 


\section{Referências Bibliográficas}

ADAMS, Neil; ALDEN, Jeremy; HARRIS, Neil. Regional Development and Spatial in an Enlarged European Union. In: ADAMS; Neil. Regional Development and Spatial Planning in an Enlarged European Union. London and New York: Routledge, pp. 3 -16, 2002

ALVES, Larissa S. Ferreira. Planning culture: concepts and perspectives historical-analytical. Mercator [Online]. Vol. 13(3), 63-73, 2014. [Acedido a 27 Novembro 2017]. Disponível em: http://www.mercator.ufc.br/mercator/article/view/1220. ISSN 1984-2201.

APPOLINÁRIO, Fabio. Dicionário de Metodologia Científica. 2. ed. São Paulo: Atlas. 2011.

ARRUDA, Augusto Guthiere Fialho. "Planejamento territorial" e "ordenamento territorial": uma busca da compreensão usual e epistemológica na gestão do território. Akrópolis-Revista de Ciências Humanas da UNIPAR [online]. Vol. 21(2), 125-132, 2013. [Acedido a 4 Fevereiro 2019]. Disponível em: http://revistas.unipar.br/index.php/akropolis/article/view/5307/3048.

BECKER, Bertha. Síntese das contribuições da oficina da Política Nacional de Ordenamento Territorial. In: Para pensar uma política nacional de ordenamento territorial, Anais da Oficina sobre a Política Nacional de Ordenamento Territorial. Brasília, pp. 71-78, 2005.

BEZERRA, Josué Alencar. A cidade-região sob as coexistências do território. Boletim Goiano de Geografia, v. 37, n. 2. 2017.

BRASIL, 2009. Lei no 10.256, de julho de 2001. Altera a Lei $n^{\circ}$ 8.212, de 24 de julho de 1991, a Lei $n \cong 0.870$, de 15 de abril de 1994, a Lei n오.317, de 5 de Dezembro de 1996, e a Lei nํ⒐528, de 10 de Dezembro de 1997. Brasília.

CABEZA, Ángel Massiris. Ordenación del territorio en América Latina. Scripta Nova Revista Electrónica de Geografía y Ciencias Sociales, Vol. 6 (125), 1-35, 2002.

CABEZA, Ángel Massiris. Gestión del Ordenamiento Territorial en América Latina: Desarrollo recientes. In: Anais do IV Seminario de Ordenamiento Territorial, Mendoza.

CABEZA, Ángel Massiris. Políticas latinoamericanas de ordenamiento territorial Realidad y desafíos. In: CABEZA, Ángel Massiris et al. Procesos de ordenamiento en América Latina y Colombia. Bogotá: Universidade Nacional de Colombia, pp. 13-30, 2012

CABEZA, Ángel Massiris. Retos del ordenamiento territorial en contextos de descentralización y autonomía en América Latina. In: CUEVA, Fernando Cordero et al (Org.). Autonomías y ordenacíon territorial y urbanística: Memorias IX Simpósio Nacional de Desarrollo Urbano y Planificación Territorial. Cuenca: Universidad de Cuenca, pp. 68-85, 2016

CARVALHO, Carla Caroline Alves et al. Plano Diretor como instrumento potencializador do desenvolvimento urbanístico e econômico das cidades pequenas. In: Anais I Congresso Internacional da Diversidade do Semiárido. Campina Grande: Editora Realize, Novembro 2016.

CEMAT - Conferência Europeia dos Ministros Responsáveis pelo Ordenamento do Território. Carta Europea de Ordenação do Território - CEOT. Lisboa: Secretaria Geral do Ministério do Planejamento e da Administração do Território, 1988.

CEPAL, Economía. Panorama del Desarrollo Territorial en América Latina y el Caribe. Santiago de Chile, Naciones Unidas, 2012

COGGIOLA, Oswaldo. Governos militares na América Latina. São Paulo: Editora Contexto, 2001. ISSN 85-7244183-2.

CORTEZ-YACILA, Héctor. Procesos urbanos y retos de la planeación territorial para la ciudad sustentable en América Latina. Boletin Cientifico Sapiens Research. Vol.3 (1), 38-43, 2017. [Acedido a 04 Fevereiro 2019]. Disponível em: https://www.srg.com.co/bcsr/index.php/bcsr/article/view/92/84. ISSN-e: 2215-9312.

COSTA, Jodival Mauricio da. Ação, espaço e território: elementos para pensar uma política de ordenamento territorial. Revista de Políticas Públicas [online]. Vol.16 (1), 15-24, 2012. [Acedido a 04 Fevereiro 2019]. Disponível em: http://www.periodicoseletronicos.ufma.br/index.php/rppublica/article/view/1173/4194. 
COUCLELIS, Helen. "Where has the future gone?" Rethinking the role of integrated land-use models in spatial planning. Environment and planning A, v. 37, n. 8, p. 1353-1371, 2005. [Acedido a 28 Outubro 2019]. Disponível em: https://journals.sagepub.com/doi/pdf/10.1068/a3785.

DANTAS, Fagner. Uso del suelo e impuesto sobre el territorio urbano en el contexto jurídico de américa latina. Urbano [online]. Vol. 17(29), 45-56, 2014. [Acedido a 04 Fevereiro 2019]. Disponível em: http://www.redalyc.org/articulo.oa?id=19836173007. ISSN 0717-3997.

DANTAS, Eugênia Maria; TROLEIS, Adriano Lima Troleis Lima; MORAIS, Ione Rodrigues Diniz. Plano Diretor e Ordenamento Territorial: uma análise do espaço urbano de Natal. Novos Cadernos NAEA [online], Vol.18 (2), 2179-7536, 2015. [Acedido a 04 Fevereiro 2019]. Disponível em: https://periodicos.ufpa.br/index.php/ncn/article/view/2124. ISSN 1516-6481.

DASÍ, Joaquín Farinós. Gobernanza territorial para el desarrollo sostenible: estado de la cuestión y agenda. Boletín de la Asociación de Geógrafos Españoles, n. 46, 2008.

FERRÃO, João. O ordenamento do território como política pública. Fundação Calouste Gulbenkian, 2011.

FERRÃO, João; MOURATO, João Morais. Ordenamento do território: o contributo dos estudos comparados internacionais. In: FERRÃO, João; HORTA, Ana (Org.). Ambiente Território e Sociedade: Novas Agendas de Investigação. Lisboa: Imprensa de Ciências Sociais, 2015. Cap. 21. 189-195.

FISHER, Luly Rodrigues da Cunha. Ordenamento territorial e planejamento municipal: estudo de caso das limitações supralocais à aplicação do art. 30, VIII da Constituição de 1988 pelo município de Parauapebas, Pará. 2014. 624 f. Tese (Doutorado) - Curso de Direito, Universidade Federal do Pará, Belém, 2014

FIGUEIREDO, Admam Harmam; ANDRADE, Joaquim Correa de; OGATA, Maria Gravina; DUNCAN; Marcelo; BRANDÃO, Paulo Cesar Garcia; AGRA, Severino; SÁ, Tatiana Deane de Abreu. Visões Governamentais. In: Para pensar uma política nacional de ordenamento territorial. Anais da Oficina sobre a Política Nacional de Ordenamento Territorial. Brasília: MI, 2005, pp. 61-70.

FRANÇA, Iara Soares de; PEREIRA; Anete Marília; SOARES, Beatriz Ribeiro; MEDEIROS; Douglas Leite. Cidade média, polarização regional e setor de educação superior: estudo de Montes Claros, no Norte de Minas Gerais. Formação (Online), v. 2, n. 16, 2009. [Acedido a 28 Outubro 2019]. Disponível em: http://revista.fct.unesp.br/index.php/formacao/article/view/863.

GALVÃO, Antonio Carlos. Prefácio. In: Para pensar uma política nacional de ordenamento territorial. Anais da Oficina sobre a Política Nacional de Ordenamento Territorial. Brasília, 13-14 de novembro de 2003. Ministério da Integração Nacional/Secretaria de Políticas de Desenvolvimento Regional. 2005

HUANG, Wei-Ju. Spatial Planning and High-tech Development: A comparative study of Eindhoven city-region, the Netherlands and Hsinchu City-region, Taiwan. Taiwan: ABE, TU Delft, 2013. ISBN 978-94-6186-197-9.

LIMA, Thales Gomes de. O estatuto da cidade: a sistemática normativa e a realidade urbana brasileira. Revista Eleitoral [online]. Vol. 29, 69-79, 2015. [Acedido a 04 Fevereiro 2019]. Disponível em: http://bibliotecadigital.tse.jus.br/xmlui/handle/bdtse/2953.

$\mathrm{KABISCH}$, Nadja. Ecosystem service implementation and governance challenges in urban green space planning-The case of Berlin, Germany. Land use policy, v. 42, p. 557-567, 2015. [Acedido a 28 Outubro 2019]. Disponível em: https://www.sciencedirect.com/science/article/abs/pii/S0264837714002002.

KLINK, Jeroen. A escalaridade e a espacialidade do (novo) desenvolvimentismo: uma exploração conceitual para o debate. Pacto federativo, integração nacional e desenvolvimento regional. São Paulo: Editora Fundação Perseu Abramo, pp. 19-38, 2013

MORAES, Antonio Carlos Robert. Ordenamento territorial: uma Conceituação para o Planejamento Estratégico, 2005. In: Para pensar uma política nacional de ordenamento territorial. Anais da Oficina sobre a Política Nacional de Ordenamento Territorial. Brasília: MI, 13-14.

PÉREZ, Soledad Sanabria. La ordenación del territorio: origen y significado. Terra Nueva Etapa [online]. Vol. 30(47), 13-32, 2014. [Acedido a 04 Fevereiro 2019]. Disponível em: http://www.redalyc.org/articulo.oa?id=72132516003. 
POLETTO, Emílio Rafael. Ordenamento territorial no Brasil e a promoção do desenvolvimento local: uma aproximação geográfica. Ágora, v. 14, n. 1, pp. 49-72, 2008

RÜCKERT, Aldomar A. A Política Nacional de Ordenamento Territorial, Brasil. Uma política territorial contemporânea em construção. Scripta Nova. Revista Electrónica de Geografía y Ciencias Sociales [online]. Vol. 11(245), 2007. [Acedido a 04 Fevereiro 2019]. Disponível em: http://www.ub.es/geocrit/sn/sn-24566.htm. ISSN: $1138-9788$.

SABOURIN, Eric. Políticas públicas terrritorializadas no Brasil e na América Latina: algumas perspectivas de evolução e de agenda para a pesquisa. In: CPDA 40 anos. Rio de Janeiro, 2016 [Acedido em Dezembro 2016]. Disponível em: http://agritrop.cirad.fr/581934/.

SANT'ANA, Jayça Lima; DE SOUZA FAVA, Gustavo; DE MELLO BUENO, Laura Machado. Planejamento, gestão e participação: a política urbana e as disputas pelo território. Revista Electrónica de Geografía y Ciencias Sociales. Barcelona: Universidad de Barcelona [online]. Vol. 14 (331), 2010. [Acedido a 04 Fevereiro 2019]. Disponível em: http://www.ub.edu/geocrit/sn/sn-331/sn-331-8.htm. ISSN: 1138-9788.

SÁNCHEZ, Juan José Díez. El Principio de Sostenibilidad en la Ordenación Territorial. Revista de Derecho Administrativo [online]. Vol 1(3), 49-66, 2007. [Acedido a 04 Fevereiro 2019]. Disponível em: http://webcache.googleusercontent.com/search?q=cache:WbJyL4Z_32AJ:revistas.pucp.edu.pe/index.php/der echoadministrativo/article/download/16315/16725+\&cd=1\&hl=pt-BR\&ct=clnk\&gl=br.

SCHEID, Andreas Hildenbrand. La experiencia del ordenamento territorial en Europa en contextos de descentralización y autonomías. In: CUEVA, Fernando Cordero et al (Org.). Autonomías y ordenacíon territorial y urbanística: Memorias IX Simpósio Nacional de Desarrollo Urbano y Planificación Territorial. Cuenca: Universidad de Cuenca, pp. 86-105, 2016.

SOUSA, Roberto González. América Latina ante el desarrollo territorial sostenible: retos e incertidumbres en un mundo globalizado. Perspectiva Geográfica [online], Vol 18(1), 91-116, 2013. [Acedido a 04 Fevereiro 2019]. Disponível em: https://doi.org/10.19053/01233769.2251.

SOUZA, Marcelo Lopes de. ABC do desenvolvimento urbano. Bertrand: Brasil.

SOUZA, Ana Paula Cavalcante Albuquerque de. Ordenamento territorial: uma análise do macrozoneamento de Ipirá. In: Anais do Simpósio Cidades Médias e Pequenas da Bahia, 2010. Disponível em: http://periodicos.uesb.br/index.php/ascmpa/article/view/3637. ISSN 2358-5293. 